\title{
Expression of adhesion molecules in pagetoid reticulosis (Woringer-Kolopp disease)
}

\author{
P.DRILLENBURG, C.M.BRONKHORST, A.C.VAN DER WAL, L.A.NOORDUYN, \\ R.HOEKZEMA* AND S.T.PALS \\ Departments of Pathology and *Dermatology, Academic Medical Centre, University of Amsterdam, 1105 AZ Amsterdam, \\ the Netherlands \\ Accepted for publication 24 September 1996
}

\begin{abstract}
Summary Cell adhesion molecules play a critical role in lymphocyte migration and homing. They convey tissue-specific homing properties to lymphocyte subsets and regulate the positioning of these subsets in the body. In a patient with pagetoid reticulosis, a rare form of cutaneous T-cell lymphoma characterized by extreme epitheliotropism, we examined the expression of adhesion molecules. The neoplastic $\mathrm{T}$ lymphocytes showed a strong expression of cutaneous lymphocyte antigen, a skinhoming receptor which interacts with E-selectin on skin endothelium. $\alpha^{\mathrm{E}} \beta_{7}$, an adhesion molecule interacting with E-cadherin on epithelial cells, was also expressed on tumour cells. These findings suggest that adhesion molecules are responsible for the unique growth pattern in pagetoid reticulosis, and for the clinical behaviour of the disorder.
\end{abstract}

The formation of distinct lymphoid compartments related to specific organs, such as mucosa- or skin-associated lymphoid tissues, depends on selective recirculation and homing of lymphocytes. This homing process is carefully regulated through specialization of both endothelial cells and lymphocyte subsets in their expression and regulation of adhesion receptors and counter-receptors. ${ }^{1}$ By mediating interactions with the extracellular matrix $(\mathrm{ECM})^{2}$ and with a variety of cells, including antigen presenting ${ }^{3}$ and epithelial cells, ${ }^{4,5}$ adhesion receptors also play a pivotal role in the subsequent migration and positioning of lymphocytes in the tissues.

Lymphomas are the malignant counterparts of normal lymphocytes. Adhesion receptors that direct normal lymphocyte homing (homing receptors) may hence play an important role in lymphoma dissemination. ${ }^{6}$ In cutaneous non-Hodgkin's lymphomas this dissemination is presumably mediated by cutaneous lymphocyte antigen (CLA), ${ }^{7,8}$ a skin homing receptor which interacts with E-selectin on skin endothelium. ${ }^{9}$

Pagetoid reticulosis (PR), or Woringer-Kolopp disease, ${ }^{10}$ is a rare lymphoproliferative disorder which is histologically characterized by an infiltrate consisting of atypical T lymphocytes localized in the epidermis. ${ }^{11}$ Consistent with a neoplastic character, these $\mathrm{T}$ cells are

Correspondence: Dr Steven T.Pals, Department of Pathology, Academic Medical Centre, University of Amsterdam, Meibergdreef 9, $1105 \mathrm{AZ}$ Amsterdam, the Netherlands. monoclonal. ${ }^{12}$ Clinically, the disease can be subdivided into an indolent localized type and a generalized type that may run an unfavourable course. ${ }^{13,14}$ The most characteristic morphological feature is the strict cutaneous localization and the extreme epitheliotropism of the tumour cells, which suggests the involvement of a highly specific set of adhesion molecules in the pathogenesis of PR. In the present study, we have examined the expression of adhesion receptors in a patient with PR.

\section{Case report}

A 74-year-old-man was referred because of a lesion on the medial part of the left lower leg. It consisted of a flat-surfaced, scaly plaque which varied in colour (from pinkish pale to reddish brown). The diameter was $6 \mathrm{~cm}$ and it had a sharp irregular border (Fig. 1). Induration was minimal and the lesion was not painful. Although the colour variation of the lesion was unusual, a clinical diagnosis of Bowen's disease or superficial basal cell carcinoma was suspected and punch biopsies were taken.

A biopsy taken from the affected skin was fixed in $10 \%$ buffered formalin and paraffin-embedded. A second biopsy was directly snap-frozen in liquid nitrogen. Immunohistochemical stainings were performed on frozen and/or paraffin sections using the streptavidinbiotin-peroxidase complex method (DAKO, Glostrup, Denmark). For tumour typing, a panel of commercially 


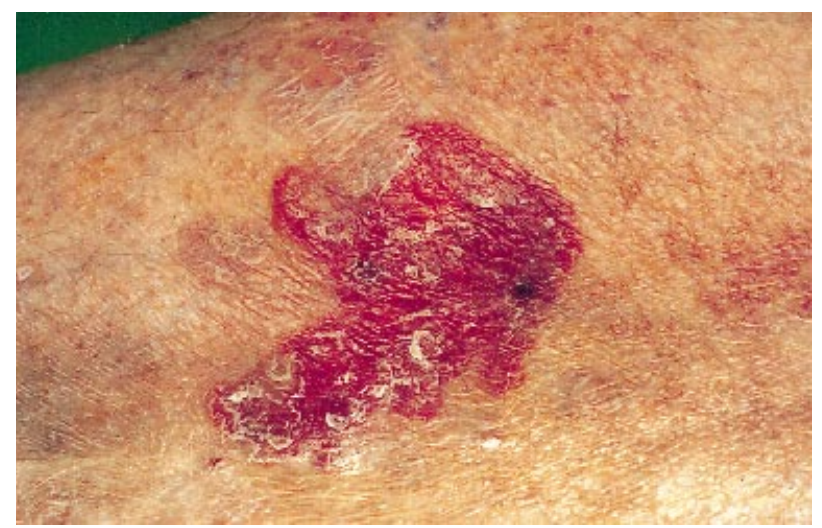

Figure 1 . The variably coloured and scaly plaque, diameter $6 \mathrm{~cm}$, on the medial part of the left lower leg.

available monoclonal antibodies (mAbs) against $\mathrm{CD} 1$, CD2, CD3, CD4, CD5, CD8, CD10, CD20, CD25, CD30, CD45, CD68, TcR $\alpha \beta, T c R \gamma \delta, ~ H L A-D R$, vimentin and keratin was used (DAKO). The mAbs against adhesion molecules used were as follows: TS 2/7 against $\alpha_{1}$ (CD49a) (ATCC Rockville, Maryland, U.S.A.); J143 against $\alpha_{3}$ (CD49c) (ATCC); Ber-Act8 against $\alpha^{\mathrm{E}} \beta_{7}$ (CD103) (DAKO); 4B4 against $\beta_{1}$ (CD29) (Coulter, Hialeah, FL,
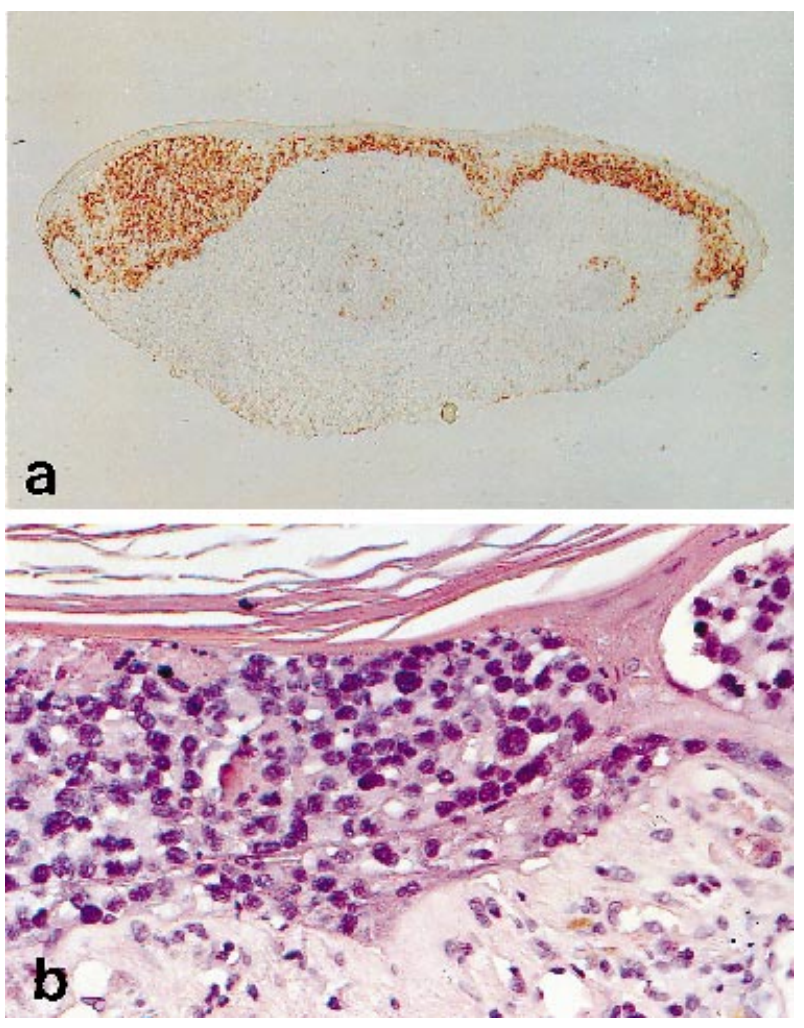

Figure 2. Pagetoid reticulosis: (a) extreme epitheliotropism, staining for CD30 (x35); (b) atypical cells with irregularly, hyperchromatic nuclei arranged individual or in clusters (x350).
Table 1. Expression of adhesion molecules

\begin{tabular}{lcc}
\hline $\begin{array}{l}\text { Adhesion } \\
\text { molecule }\end{array}$ & $\begin{array}{c}\text { Positivity } \\
\text { tumour cells (\%) }\end{array}$ & \begin{tabular}{c} 
Intensity* \\
\hline$\alpha_{1}$-chain
\end{tabular} \\
$\alpha_{3}$-chain & $0 \%$ & 0 \\
$\alpha_{4}$-chain & $0 \%$ & 0 \\
$\alpha_{4} \beta_{7}$ & $10 \%-50 \%$ & $1+$ \\
$\alpha_{6}$-chain & $0 \%$ & 0 \\
$\alpha^{\mathrm{E}} \beta_{7}$ & $0 \%$ & 0 \\
$\alpha_{\mathrm{L}}$-chain & $\geq 90 \%$ & $2+$ \\
$\beta_{1}$-chain & $\geq 90 \%$ & $2+$ \\
$\beta_{2}$-chain & $\geq 90 \%$ & $2+$ \\
L-selectin & $50 \%-90 \%$ & $2+$ \\
ICAM-1 & $10 \%-50 \%$ & $2+$ \\
VCAM-1 & $10 \%-50 \%$ & $2+$ \\
CLA & $50 \%-90 \%$ & $1+$ \\
& $\geq 90 \%$ & $2+$ \\
\hline
\end{tabular}

$* 0$, no staining; $1+$, moderate staining; $2+$, strong staining.

U.S.A.); BBIG-I1 against ICAM-1 (CD54) (British Biotechnology, Abingdon, Oxon, U.K.); 4B9 against VCAM-1 (CD106); ${ }^{15}$ and HECA452 against CLA. ${ }^{16} \mathrm{HP} 2 / 1$ against $\alpha_{4}(\mathrm{CD} 49 \mathrm{~d}) ; \mathrm{M} 17$ against $\alpha_{\mathrm{L}}$ (CD11a); and M18 against $\beta_{2}$ (CD18) were kindly provided by Dr F.Sanchez-Madrid (Universidad Autonoma de Madrid, Spain). 1A10 against $\alpha_{6}$ (CD49f) and Act-1 against $\alpha_{4} \beta_{7}(\mathrm{CD} 49 \mathrm{~d} /$ $\beta_{7}$ ) were a gift from Dr A. Sonnenberg (NKI, Amsterdam, the Netherlands) and Dr A.I. Lazarovits (University of Western, London, Ontario, Canada), respectively.

The skin biopsy showed an intraepithelial lesion consisting of atypical cells with a moderate amount of cytoplasm and large irregular, hyperchromatic nuclei with inconspicuous nucleoli (Fig. 2). The atypical cells were arranged as individual cells or clusters between the keratinocytes. There was no evident hyper- and/or parakeratosis. In the dermis underneath the lesion, a reactive infiltrate consisting of plasma cells and small lymphocytes was present. Immunohistochemistry on paraffin and/or frozen sections showed uniform expression of CD2, CD5, CD8, CD25, CD30, CD45, HLA-DR and TCR- $\alpha \beta$ on the tumour cells, and hence identified them as activated cytotoxic T-lymphocytes. The tumour cells showed an adhesion phenotype as described in Table 1.

After PR was diagnosed based on the histopathological features, staging, which included a thorough physical examination, blood and bone marrow smears and a chest X-ray were performed. No evidence of internal involvement was found. The lesion was treated by radiation with $6 \mathrm{MeV}$ electron beam therapy, using 20 doses of $2 \mathrm{~Gy}$ in 25 days. This resulted in a complete clinical remission. 
Figure 3. Immunohistochemical stainings of the skin lesion: (a) cutaneous lymphocyte antigen; (b) $\alpha_{4} \beta_{7}$; (c) $\alpha^{\mathrm{E}} \beta_{7}$; (d) CD30 (x175).
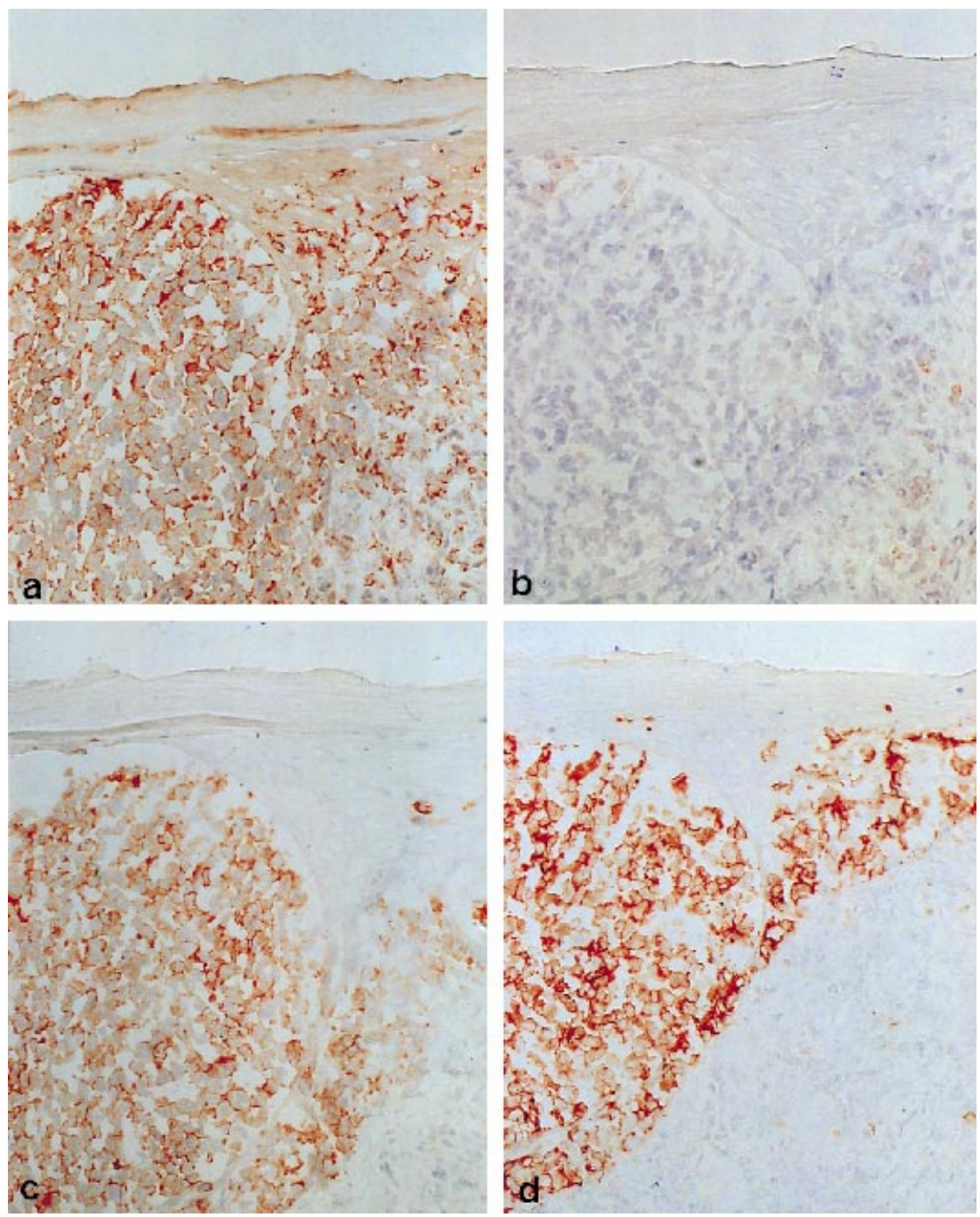

\section{Discussion}

The atypical cells in the present case of PR strongly expressed cutaneous lymphocyte antigen (CLA) (Fig. 3a). Cutaneous lymphocyte antigen is a skin-homing receptor which directs $\mathrm{T}$ lymphocytes to the skin through interaction with E-selectin on dermal vessels. ${ }^{1,9}$ In the peripheral blood, CLA is expressed on a subset of memory T lymphocytes. ${ }^{7-9}$ Cutaneous lymphocyte antigen expression is presumably acquired during virgin to memory transition of $\mathrm{T}$ cells in skin-associated peripheral lymph nodes. ${ }^{17}$ The CLA ${ }^{+}$T cell population in the blood is nonoverlapping with a population of gut-homing memory $\mathrm{T}$ cells which expresses $\alpha_{4} \beta_{7}$, the receptor for the mucosal addressin MAdCAM-1. ${ }^{1,18}$ Consistent with this dichotomy, no expresssion of $\alpha_{4} \beta_{7}$ was observed in the present case (Fig. 3b). Also, we observed no $\alpha_{4} \beta_{7}$ expression in mycosis fungoides (unpublished observation). The expression of CLA in PR reflects its ontogenetic relation to the skin-homing T-cell subset and may contribute to the specific pattern of dissemination of the malignant lymphocytes. ${ }^{7,8}$

Interestingly, all tumour cells were found to strongly express $\alpha^{\mathrm{E}} \beta_{7}$ (Fig. 3c). Under physiological conditions, $\alpha^{\mathrm{E}} \beta_{7}$ is expressed on nearly all intestinal intraepithelial lymphocytes and on approximately $50 \%$ of the T cells in the lamina propria. In the normal skin expression of $\alpha^{\mathrm{E}} \beta_{7}$ is not detected on cells in the epidermis. Cepek et al. demonstrated that $\alpha^{\mathrm{E}} \beta_{7}$ can bind E-cadherin on epithelial cells and may hence mediate positioning of lymphocytes in the epithelium. ${ }^{4}$ We presume that in $\mathrm{PR}$, the strong $\alpha^{\mathrm{E}} \beta_{7}$ expression is a key factor in the epitheliotropism and the specific distribution of the lymphocytes between the keratinocytes (pagetoid pattern). 
LFA-1 may also contribute to this interaction since the epidermal keratinocytes in the lesions expressed ICAM-1 (not shown). In this context, the recent finding of a correlation in mycosis fungoides between loss of epitheliotropism and loss of $\alpha^{\mathrm{E}} \beta_{7}$ expression is of interest since it also supports a role for this integrin in tumour cell interaction with the epidermis. ${ }^{19}$

To enter the epithelium, lymphocytes have to cross the epithelial basement membrane (EBM). Recently, interaction of the integrin $\alpha_{3} \beta_{1}$ to laminin-5 in the EBM, was suggested to present the first step in this process. ${ }^{20}$ In the present case, the tumour cells did not express $\alpha_{3}$. In PR the tumour cells are localized in the epithelium; downregulation of $\alpha_{3}$ might occur after transition of the EBM.

The present tumour showed strong expression of CD30 (Fig. 3d). Among primary cutaneous T-cell lymphomas, the classical cases of mycosis fungoides/Sézary syndrome can be separated from a group of large cell lymphomas with a distinctive clinical and histological picture. Expression of CD30 on the tumour cells further subdivides this latter group since, irrespective of the morphology, expression of CD30 is related to a favourable prognosis. ${ }^{11}$ These $\mathrm{CD}^{+} 0^{+}$lymphomas have a tendency to remit spontaneously and are highly responsive to radiotherapy. ${ }^{11}$ CD30, a member of the TNF/NGF family, might play a direct role in causing this favourable response to therapy since triggering can induce apoptosis. ${ }^{21}$

In conclusion, this case shows that the atypical lymphocytes in PR are equipped with a set of adhesion molecules that allow specific skin-homing as well as highly effective interaction with epidermal keratinocytes. This suggests that these adhesion molecules are an important factor in determining the unique growth pattern of PR and its characteristic clinical behaviour.

\section{Acknowledgment}

This research was supported by Grant IKA 91/9 of the Dutch Cancer Society.

\section{References}

1 Butcher EC, Picker LJ. Lymphocyte homing and homeostasis. Science 1996; 272: 60-6.

2 Reynolds PJ, Shimizu Y, Mobley JL. Lymphocytes and extracellular matrix. In: Lymphocyte Adhesion Molecules (Shimizu Y, ed.). Austin: RG Landes Company, 1993; 192-220.

3 Koopman G, Parmentier HK, Schuurman H-J et al. Adhesion of human B-cells to follicular dendritic cells involves both the LFA-1/ ICAM-1 and VLA-4/VCAM-1 pathways. J Exp Med 1991; 173: 1297-304.

4 Cepek KL, Shaw SK, Parker CM et al. Adhesion between epithelial cells and $\mathrm{T}$ lymphocytes mediated by E-cadherin and the $\alpha^{\mathrm{E}} \beta_{7}$ integrin. Nature 1994; 372: 190-3.

5 Cerf-Bensussan N, Jarry A, Brousse N et al. A monoclonal antibody (HML-1) defining a novel membrane molecule present on human intestinal lymphocytes. Eur J Immunol 1987; 17: 1279-85.

6 Pals ST, Horst E, Scheper RJ, Meijer CJLM. Mechanisms of human lymphocyte migration and their role in the pathogenesis of disease. Immunol Rev 1989; 108: 111-33.

7 Noorduyn LA, Beljaards RC, Pals ST et al. Differential expression of the HECA-452 antigen (cutaneous lymphocyte associated antigen. CLA) in cutaneous and non-cutaneous T-cell lymphomas. Histopathology 1992; 21: 59-64.

8 Picker LJ, Michie SA, Rott LS, Butcher EC. A unique phenotype of skin-associated lymphocytes: preferential expression of the HECA452 epitope by benign and malignant $\mathrm{T}$ cells at cutaneous sites. Am J Pathol 1990; 136: 1053-68.

9 Berg EL, Yoshino T, Rott LS et al. The cutaneous lymphocyte antigen is a skin lymphocyte homing receptor for the vascular lectin endothelial cell-leucocyte adhesion molecule 1. J Exp Med 1991; 174: 1461-6.

10 Woringer F, Kolopp P. Lesion erythemato-squameuse polycyclique de l'avant-bras evoluant depuis 6 ans chez un garconnet de 13 ans: histologiquement infiltrat intra-epidermique d'apparence tumorale. Ann Dermatol Venereol 1939; 10: 945-8.

11 Willemze R, Beljaards RC, Meijer CJLM. Classification of primary cutaneous T-cell lymphomas. Histopathology 1994; 24: 405-15.

12 Wood GS, Weiss LM, Hu C-H et al. T-cell antigen deficiencies and clonal rearrangements of T-cell receptor genes in pagetoid reticulosis (Woringer-Kolopp disease). N Engl J Med 1988; 318: 164-7.

13 Wood GS. Benign and malignant cutaneous lympho-proliferative disorders including mycosis fungoides. In: Neoplastic Hematopathology (Knowles DM, ed.). Baltimore: Williams and Wilkins, 1992; 932-3.

14 Yagi H, Hagiwara T, Shirahama S et al. Disseminated pagetoid reticulosis: need for long-term follow-up. J Am Acad Dermatol 1994; 30: 345-9.

15 Carlos TM, Schwartz BR, Kovach NL et al. Vascular cell adhesion molecule-1 (VCAM-1) mediates lymphocyte adherence to cytokineactivated cultured human endothelial cells. Blood 1990; 76: 965-70.

16 Duijvestijn AM, Horst E, Pals ST et al. High endothelial cell differentiation in human lymphoid and inflammatory tissues defined by monoclonal antibody HECA-452. Am J Pathol 1988; 130: $147-55$.

17 Picker LJ, Treer JR, Ferguson-Darnell B et al. Control of lymphocyte recirculation in man. II. Differential regulation of the cutaneous lymphocyte-associated antigen, a tissue-selective homing receptor for skin-homing T cells. J Immunol 1993; 150: 1122-36.

18 Schweighoffer T, Tanaka Y, Tidswell M et al. Selective expression of integrin $\alpha_{4} \beta_{7}$ on a subset of human CD4 + memory T cells with hallmarks of gut-tropism. J Immunol 1993; 151: 717-29.

19 Simonitsch I, Volc-Platzer B, Mosberger I, Radaszkiewicz T. Expression of monoclonal antibody HML-1 defined $\alpha^{\mathrm{E}} \beta_{7}$ integrin in cutaneous T-cell lymphoma. Am J Pathol 1994; 145: 1148-58.

20 Wayner EA, Gil SG, Murphy GF et al. Epiligrin, a component of epithelial basement membranes, is an adhesive ligand for $\alpha_{3} \beta_{1}$ positive T lymphocytes. J Cell Biol 1993; 121: 1141-52.

21 Gruss HJ, Boiani N, Williams DE et al. Pleiotropic effects of the CD30 ligand on CD30-expressing cells and lymphoma cell lines. Blood 1994; 83: 2045-56. 